\title{
Rituximab Used Successfully in the Treatment of Anti-NMDA Receptor Encephalitis
}

\author{
Ryotaro Ikeguchi ${ }^{1,2}$, Koichi Shibuya ${ }^{1}$, Shigeo Akiyama ${ }^{1}$, Shuji Hino ${ }^{1}$, Hiromasa Kubo ${ }^{1}$, \\ Takahiro Takeda ${ }^{2}$, Noriyuki Shibata ${ }^{3}$ and Kenji Yamamoto ${ }^{1}$
}

\begin{abstract}
We report the case of a young woman with anti-N-methyl-D-aspartate receptor (NMDAR) encephalitis, without tumor, who was successfully treated with rituximab. Because conventional immunotherapy, including corticosteroids, immunoglobulin (IVIg), and plasma exchange showed little improvement in our patient, we introduced another treatment using rituximab. A week after the first administration of rituximab, her symptoms improved gradually and significantly. This case provides in vivo evidence that rituximab is an effective agent for treating anti-NMDAR encephalitis, even in those cases where conventional immunotherapies have been ineffective. Rituximab should be regarded as a beneficial therapeutic agent for this disease.
\end{abstract}

Key words: encephalitis, NMDA receptor, rituximab, treatment, tumor

(Intern Med 51: 1585-1589, 2012)

(DOI: 10.2169/internalmedicine.51.6874)

\section{Introduction}

Anti-N-methyl-D-aspartate receptor (NMDAR) encephalitis is an autoimmune encephalitis that was first characterized by Dalmau and his colleagues in 2007 (1). The disorder predominantly affects children and young adult women (2). A previous report suggests that the encephalitis is associated with a tumor in almost $42 \%$ of the patients, but the precise pathological background and its relationship to the encephalitis remain elusive (2).

Clinical features of the encephalitis are characterized by psychiatric symptoms, disturbance of consciousness, generalized seizures, abnormal involuntary movements, autonomic dysfunction, and central hypoventilation (2-4). The diagnosis is based upon the clinical course of the condition and these neurological features. In addition, the demonstration of antiNMDAR antibodies in the serum and cerebrospinal fluid (CSF) is essential for diagnosis.

The condition is treated by tumor removal (in those patients with a tumor), whereas first-line immunotherapy (corticosteroids plus intravenous immunoglobulin (IVIg) or plasma exchange) has been proposed in previous reports (2).
When little or no response is seen after administration of these therapies, treatment with second-line immunotherapy (e.g., rituximab and/or cyclophosphamide) should be considered $(2,3,5-8)$.

Here, we report the case of a young woman with antiNMDAR encephalitis that was not associated with a tumor, who showed significant improvement in symptoms after administration of rituximab.

\section{Case Report}

A 19-year-old Japanese woman first presented with diarrhea and nausea. Ten days after the onset of these symptoms, she was rushed to a nearby emergency hospital due to fever and generalized tonic seizure. On the following day, she manifested unusual behaviors, such as removing the intravenous infusion line by herself, or leaving her room naked; she was therefore transferred to our hospital for intensive medical care.

On arrival, her temperature was $37.4^{\circ} \mathrm{C}$, and pulse rate was 90 beats/min. Physical examination did not indicate any abnormalities. Her level of consciousness was E4V4M6 on the Glasgow Coma Scale, and she showed psychiatric symp-

${ }^{1}$ Department of Neurology, Saitama Red Cross Hospital, Japan, ${ }^{2}$ Department of Neurology, Tokyo Women's Medical University, Japan and ${ }^{3}$ Department of Pathology, Tokyo Women's Medical University, Japan

Received for publication November 4, 2011; Accepted for publication February 13, 2012

Correspondence to Dr. Ryotaro Ikeguchi, riker715@hotmail.com 


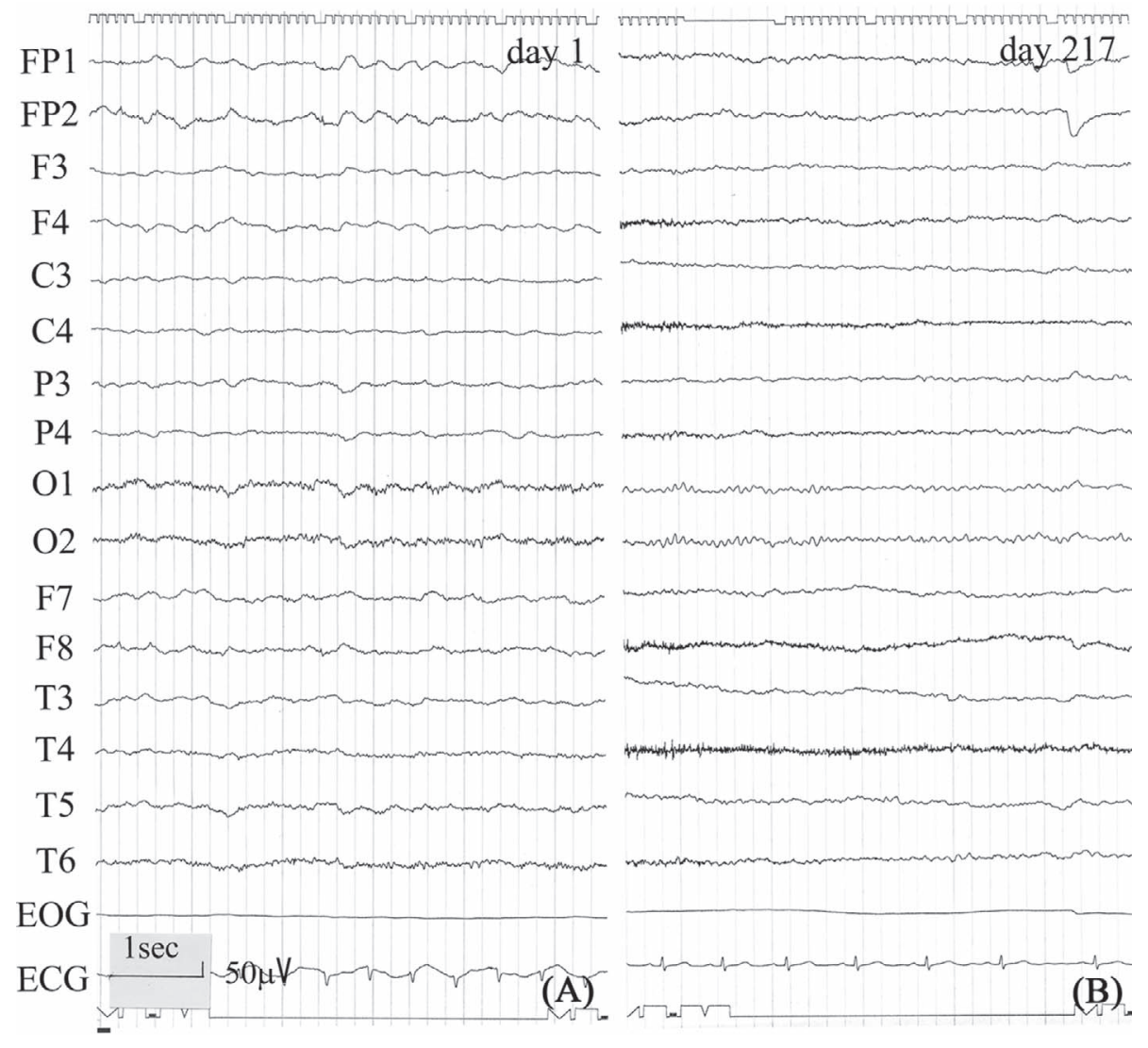

Figure 1. Electroencephalogram (EEG). Poor $\alpha$ organization with diffuse slowing of background activity was noted prior to the administration of immunotherapy, including rituximab (A). After rituximab was introduced, the abnormal activity on the EEG was markedly improved (B).

toms, such as crying out, perseveration, and stereotypic behaviors.

Hematological tests showed a white blood cell (WBC) count of 10,050 cells $/ \mu \mathrm{L}$ (82\% neutrophils, $11 \%$ lymphocytes). C-reactive protein (CRP) was $0.1 \mathrm{mg} / \mathrm{dL}$. Creatine kinase level was 350 U/L. The CSF contained 14 leukocytes $/ \mu \mathrm{L}$ (including $85 \%$ mononuclear cells) and $29 \mathrm{mg} / \mathrm{dL}$ of protein. The glucose level in the CSF was $76 \mathrm{mg} / \mathrm{dL}$, while serum glucose level was $102 \mathrm{mg} / \mathrm{dL}$. The IgG-index was 0.73 , and IL-6 was slightly elevated $(9.9 \mathrm{pg} / \mathrm{mL})$. In addition, CSF culture proved to be negative for bacteria. Serological examination and polymerase chain reaction-based analysis of CSF for viruses, including herpes simplex virus, were not suggestive of any viral infection. Brain magnetic resonance imaging (MRI) demonstrated no remarkable abnormalities, even after enhancement with gadolinium chelate. Electroencephalogram (EEG) showed diffuse slow waves (Fig. 1). Epileptogenic discharges were not detected. Whole body investigation by chest-abdominal computed tomography and MRI of the pelvis revealed no indication of a tumor lesion.

Because she manifested repetitive generalized convulsions and hyperventilation attacks several times a day, intravenous administration of acyclovir and phenytoin was initiated. Five days after admission (day 5), apnea and hyperventilation became apparent, followed by an autonomic instability charac- terized by intermittent bradycardia and hypersalivation. Two days later, she developed disturbance of consciousness, and artificial ventilation was required. She was treated with carbamazepine and continued intravenous administration of midazolam; however, these treatments had little effect on controlling the attacks. Therefore, subsequent intravenous infusion of vecuronium bromide was implemented. On day 9, orofacial dyskinesia became evident. Although treatment with methylprednisolone $(1,000 \mathrm{mg} /$ day for 3 days, 2 cycles), IVIg ( $0.4 \mathrm{~g} / \mathrm{kg}^{-1} / \mathrm{day}^{-1}$ for 5 days) and plasma exchange (7 times) was introduced from day 7 to day 74 , her symptoms did not improve. The clinical profile of her symptoms was suggestive of anti-NMDAR encephalitis. We started weekly rituximab (adhering to the administration protocol of rituximab approved by the Ethics Committee of Saitama Red Cross Hospital), for a total of 4 doses (a monoclonal anti-CD20 antibody, $375 \mathrm{mg} / \mathrm{m}^{-2} /$ week $^{-1}$ ), on day 100. A week after the first administration of rituximab, her clinical symptoms, including fever, consciousness disturbance, involuntary movement, and autonomic instability, markedly improved (Fig. 2). In parallel with these symptomatic improvements, the findings on EEG were normalized (Fig. 1). Antibody to the NMDAR was detected both in her serum and CSF, which were collected before immunotherapy, including corticosteroids, IVIg, and plasma exchange had been initiated. These samples were collected on day 7 and sent to Dr. 


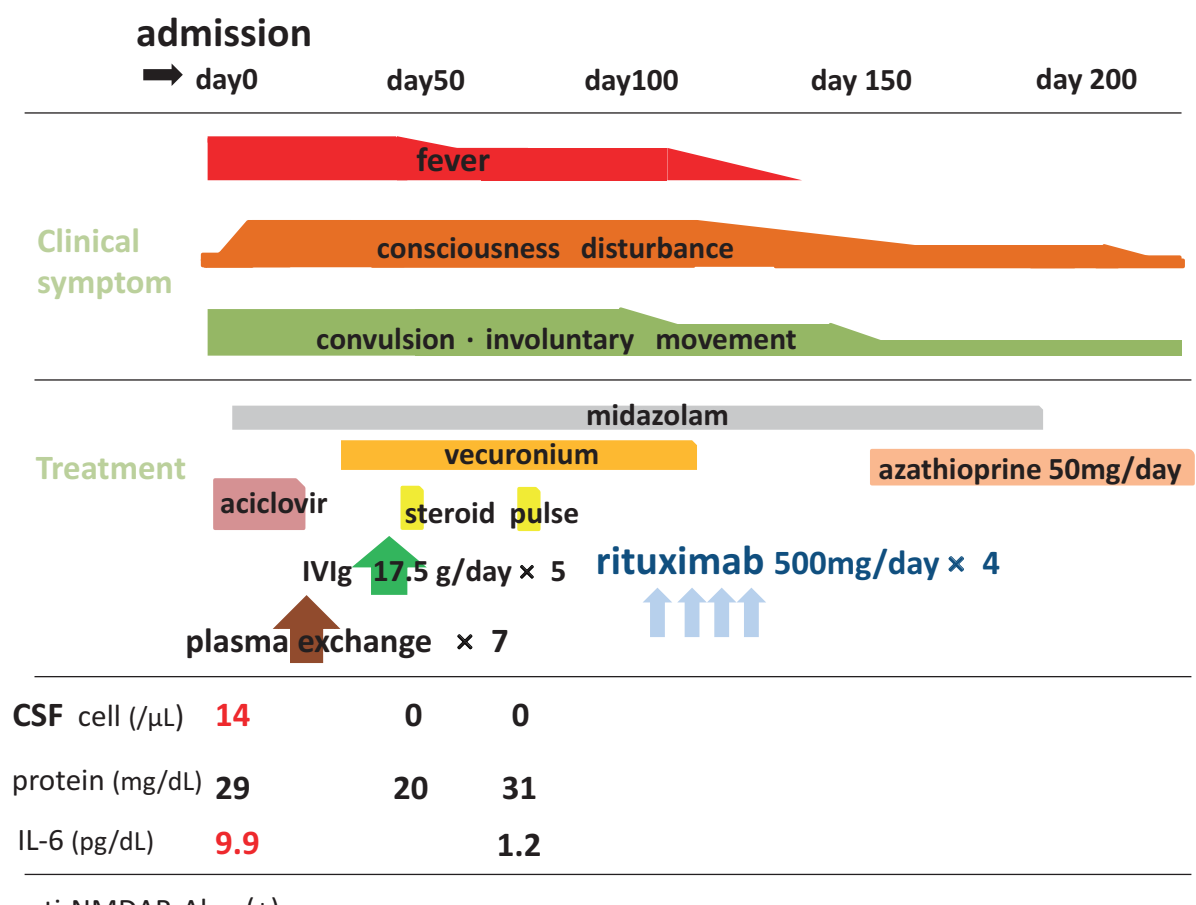

anti-NMDAR-Ab (+)

Figure 2. Schematic representation of clinical course. The patient's clinical symptoms improved consistently from a week after the first administration of rituximab.
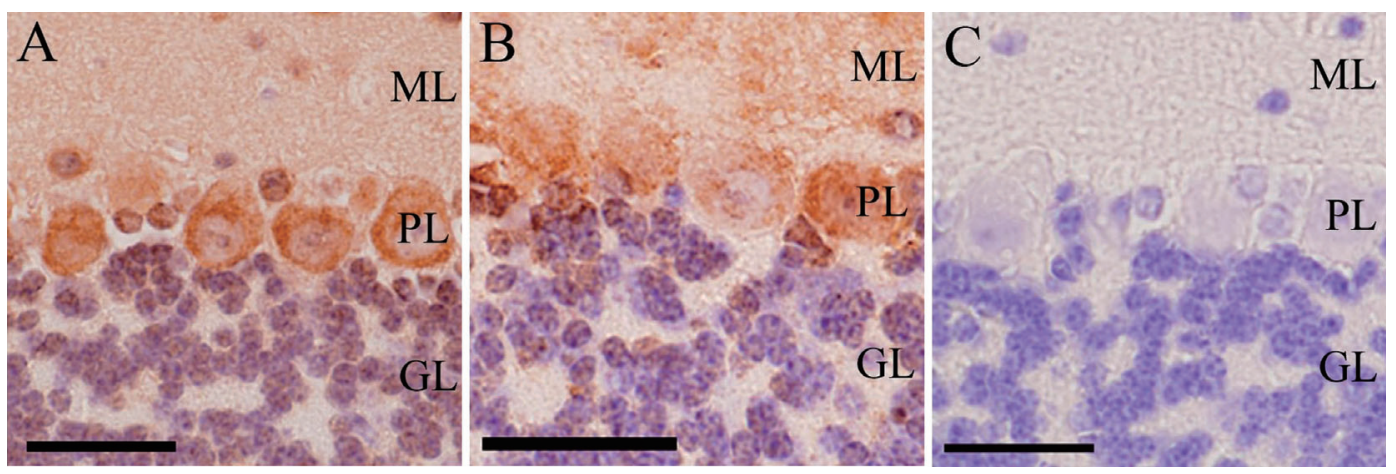

Figure 3. Immunohistochemistry. Immunohistochemical observations on $10 \%$ formalin-fixed, paraffin-embedded sections of mouse cerebellar $(\mathrm{A}, \mathrm{B}, \mathrm{C})$ tissue using a rabbit anti-glutamate receptor $\delta 2$ (GluRס2)-antibody(sc-50415; Santa Cruz Biotechnology, Santa Cruz, CA, USA), at a dilution of 1:100 (A), the patient's serum, at a dilution of 1:2,000 (B), and normal human serum, at a dilution of 1:2,000 (C). Prior to incubation with these primary antibody solutions, sections were microwaved $\left(400 \mathrm{~W}, 9^{\circ} \mathrm{C}, 10 \mathrm{~min}\right)$ in citrate buffer, $\mathrm{pH}$ 6.0. Immunoreaction was visualized by the avidin-biotinimmunoperoxidase method (Vector) and polymer-immunocomplex method (Dako) for human- and rabbit-derived antibodies, respectively. 3,3'-Diaminobenzidine tetrahydrochloride was used as chromogen, and hematoxylin as counterstain. The patient's serum samples were collected on day 57 , prior to first administration of rituximab. The cytoplasm of Purkinje cells and the cerebellar molecular layer were distinctly immunopositive for the rabbit antibody (A), as well as for the patient's serum (B). No immunoreaction was evident in the control section stained with normal human serum (C). GL: granular layer, ML: molecular layer, PL: Purkinje layer, Bars =10 $\mu \mathrm{m}$

Dalmau's laboratory (Department of Neurology, University of Pennsylvania), where the presence of anti-NMDAR antibodies was revealed on day 113 . Therefore, she was diagnosed with anti-NMDAR encephalitis. Improvements of respiratory failure were relatively slow, and she was started on azathioprine $(50 \mathrm{mg} /$ day) treatment from day 160 . On day
207, she was successfully weaned off artificial ventilation. Although disorientation and mild involuntary movement persisted, she was able to not only eat and walk unassisted, but also to draw a simple picture and write characters. On day 227, she was transferred to another hospital for rehabilitation. 
Although brain MRI did not reveal any abnormal intensities in this case, normal mouse brain parenchyma showed focal immunoreactions to serum samples from this patient that were collected on day 57 (after administration of firstline immunotherapy and before administration of rituximab) (Fig. 3). The cytoplasm of Purkinje cells and the dendritic layer were markedly immunopositive to the patient's serum (Fig. 3).

\section{Discussion}

In this study, we describe the reduction in symptoms and EEG abnormalities in a young woman with anti-NMDAR encephalitis without an associated tumor by administration of rituximab. A previous report suggests that a tumor, mostly ovarian teratoma (2), could be identified in $42 \%$ of patients with anti-NMDAR encephalitis; however, no causative tumor lesions could be identified in the remainder of such patients. In patients without a tumor, first-line immunotherapy, using corticosteroids, IVIg, plasma exchange may not be effective, thus second-line immunotherapy (e.g., rituximab and/or cyclophosphamide) is usually needed (2, 3, 5-9).

The immunopathogenesis of this encephalitis is possibly related to antibody immune-responses of $\mathrm{B}$ cell and antibody-secreting cells (e.g., plasma cells), which are derived from activated $\mathrm{B}$ cells (10-12). In the present case, normal mouse brain showed immunoreactions to serum samples from this patient, which had been collected after administration of first-line immunotherapy, and before the administration of rituximab. This immunoreaction was similar to that to commercially available anti-glutamate receptor (GluR) $\delta 2$-antibody. GluR $\delta 2$ shares a partial epitope with NMDAR, which is a well-known protein present on cerebellar Purkinje cells. Thus, our experimental results supported the immunological evidence that this patient's serum sample includes an antibody with affinity to NMDAR. Rituximab causes a decrease in $\mathrm{B}$ cells and prevents maturation of these cells into antibody-secreting cells (10); it also suppresses B cell function more selectively and continuously than first-line immunotherapy (13-19). In addition, this agent causes a form of immune system resetting due to the depletion of memory B cells $(19,20)$. Depletion of B cells inhibits its antigen-presenting role and cytokine secretion function, which prevents stimulating $\mathrm{T}$ cells $(20,21)$. Therefore, rituximab may be effective for treatment of antiNMDAR encephalitis that is resistant to first-line immunotherapy.

It is well known that the typical adverse effects of rituximab are infusion-related reactions, leukocytopenia, hypogammaglobulinemia, and infection, whereas progressive multifocal leukoencephalopathy (PML) and reactivation of hepatitis B virus are rare, but important, complications of rituximab (22). Although infusion-related reactions, such as fever, were seen in this case, these resolved immediately, and there were no serious adverse effects during follow-up.
Cyclophosphamide is also recommended as second-line immunotherapy for anti-NMDAR encephalitis $(2,3,8)$; however, dose-dependent gonadal toxicity and infertility might be serious disadvantages for young patients, in addition to the other negative side effects, including malignancy, hemorrhagic cystitis, myelosuppression, alopecia, and infection (23-26). Thus, considering the B cell-selective pharmacological effects and the limited side effects of rituximab, this therapy might be particularly useful in young antiNMDAR encephalitis patients without tumor lesions $(2,5,7,13,14,20,27-30)$.

More detailed clinical analysis is necessary to elucidate the etiology of anti-NMDAR encephalitis. Awareness of the probable effectiveness of rituximab for this type of encephalitis may both enhance our understanding of the disease and facilitate the appropriate treatment of patients with antiNMDAR encephalitis.

\section{The authors state that they have no Conflict of Interest (COI).}

\section{Acknowledgement}

We are most grateful to Professor Joseph Dalmau (Department of Neurology, University of Barcelona, Spain) for analysis of the antibodies against NMDA receptor.

\section{References}

1. Dalmau J, Tuzun E, Wu HY, et al. Paraneoplastic anti-N-methylD-aspartate receptor encephalitis associated with ovarian teratoma. Ann Neurol 61: 25-36, 2007.

2. Dalmau J, Lancaster E, Hernandez EM, et al. Clinical experience and laboratory investigations in patients with anti-NMDAR encephalitis. Lancet Neurol 10: 63-74, 2011.

3. Dalmau J, Gleichman AJ, Hughes EG, et al. Anti-NMDA-receptor encephalitis: case series and analysis of the effects of antibodies. Lancet Neurol 7: 1091-1098, 2008.

4. Iizuka T, Sakai F, Ide T, et al. Anti-NMDA receptor encephalitis in Japan. Neurology 70: 504-511, 2008.

5. Wong-Kisiel LC, Ji T, Renaud DL, et al. Response to immunotherapy in a 20-month-old boy with anti-NMDA receptor encephalitis. Neurology 74: 1550-1551, 2010.

6. Ishiura H, Matsuda S, Higashihara $M$, et al. Response of antiNMDA receptor encephalitis without tumor to immunotherapy including rituximab. Neurology 71: 1921-1923, 2008.

7. Frechette ES, Zhou L, Galetta SL, et al. Prolonged follow-up and CSF antibody titers in a patient with anti-NMDA receptor encephalitis. Neurology 76: S64-S66, 2011.

8. Kashyape P, Taylor E, Ng J, Kirkham F, Whitney A. Successful treatment of two paediatric cases of anti-NMDA receptor encephalitis with cyclophosphamide: the need for early aggressive immunotherapy in tumor negative paediatric patients. Eur $\mathrm{J}$ Paediatr Neurol 16: 74-78, 2012.

9. Iizuka T, Yasuda T, Mochizuki H. Recent progress in anti-NMDA receptor encephalitis. Saishin Igaku 66: 973-983, 2011 (in Japanese).

10. Hernandez EM, Horvath J, Malawsky YS, Shagha N, Lage MM, Dalmau J. Analysis of complement and plasma cells in the brain of patients with anti-NMDAR encephalitis. Neurology 77: 589593, 2011.

11. Tüzün E, Zhou L, Baehring JM, Bannykh S, Rosenfeld MR, Dalmau J. Evidence for antibody-mediated pathogenesis in antiNMDAR encephalitis associated with ovarian teratoma. Acta Neu- 
ropathol 118: 737-743, 2009.

12. Camdessanche JP, Streichenberger N, Cavillon G, et al. Brain immunohistopathological study in a patient with anti-NMDAR encephalitis. Eur J Neurol 18: 929-931, 2011.

13. Looney RJ, Anolik JH, Campbell D, et al. B cell depletion as a novel treatment for systemic lupus erythematosus:a phase I/II dose-escalation trial of rituximab. Arthritis Rheum 50: 2580-2589, 2004.

14. Pranzatelli MR, Tate ED, Travelstead AL, et al. Rituximab (antiCD20) adjunctive therapy for opsoclonus-myoclonus syndrome. J Pediatr Hematol Oncol 28: 585-593, 2006.

15. Dalakas MC, Rakocevic G, Salajegheh M, et al. Placebocontrolled trial of rituximab in IgM anti-myelin-associated glycoprotein antibody demyelinating neuropathy. Ann Neurol 65: 286-293, 2009.

16. Blum $\mathrm{S}$, Gillis D, Brown $\mathrm{H}$, et al. Use and monitoring of low dose rituximab in myasthenia gravis. J Neurol Neurosurg Psychiatry 82: 659-663, 2010.

17. Motoyama R, Yamakawa K, Suzuki S, Kusunoki S, Tanaka M. Rapid improvement by rituximab treatment in a case of demyelinating polyneuropathy with anti-myelin-associated glycoprotein antibody. Clin Neurol 51: 761-764, 2011 (in Japanese).

18. Stein B, Bird SJ. Rituximab in the treatment of MuSK antibodypositive myasthenia gravis. J Clin Neuromuscul Dis 12: 163-164, 2011.

19. Anolik JH, Barnard J, Owen T, et al. Delayed memory B cell recovery in peripheral blood and lymphoid tissue in systemic lupus erythematosus after B cell depletion therapy. Arthritis Rheum 56: 3044-3056, 2007.

20. Perosa F, Prete M, Racanelli V, Dammacco F. CD20-depleting therapy in autoimmune diseases: from basic research to the clinic. J Intern Med 267: 260-277, 2010.

21. Dalakas MC. B cells in the pathophysiology of autoimmune neurological disorders: a credible therapeutic target. Pharmacol Ther
112: 57-70, 2006.

22. Izutsu K. Late complications of rituximab therapy. Hematol Oncol 60: 41-47, 2010 (in Japanese).

23. Boumpass DT, Austin HA, Vaughan EM, Yarboro CH, Klippel JH, Balow JE. Risk for sustained amenorrhea in patients with systemic lupus erythematosus receiving intermittent pulse cyclophosphamide therapy. Ann Intern Med 119: 366-369, 1993.

24. Gourley MF, Austin HA, Scott D, et al. Methylprednisolone and cyclophosphamide, alone or in combination, in patients with lupus nephritis. Ann Intern Med 125: 549-557, 1996.

25. Latta K, von Schnakenburg C, Ehrich JH. A meta-analysis of cytotoxic treatment for frequently relapsing nephrotic syndrome in children. Pediatr Nephrol 16: 271-282, 2001.

26. Riley P, Maillard SM, Wedderburn LR, Woo P, Murray KJ, Pilkington CA. Intravenous cyclophosphamide pulse therapy in juvenile dermatomyositis. A review of efficacy and safety. Rheumatology 43: 491-496, 2004.

27. Parodi E, Rivetti E, Amendola G, et al. Long-term follow-up analysis after rituximab therapy in children with refractory symptomatic ITP: identification of factors predictive of a sustained response. Br J Haematol 144: 552-558, 2009.

28. Gottenberg JE, Guillevin L, Lambotte $O$, et al. Tolerance and short term efficacy of rituximab in 43 patients with systemic autoimmune diseases. Ann Rheum Dis 64: 913-920, 2005.

29. Vigna-Perez M, Hernandez-Castro $B$, Paredes-Saharopulos $O$, et al. Clinical and immunological effects of Rituximab in patients with lupus nephritis refractory to conventional therapy: a pilot study. Arthritis Res Ther 8: R83, 2006.

30. Gunnarsson I, Sundelin B, Jonsdottir T, Jacobson SH, Henriksson EW, van Vollenhoven RF. Histopathologic and clinical outcome of rituximab treatment in patients with cyclophosphamide-resistant proliferative lupus nephritis. Arthritis Rheum 56: 1263-1272, 2007.

(C) 2012 The Japanese Society of Internal Medicine http://www.naika.or.jp/imindex.html 